\title{
O NOVO CONSTITUCIONALISMO LATINO AMERICANO E SUA CONTRIBUIÇÃO NAS POLÍTICAS DE PROTEÇÃO E DE RECONHECIMENTO DE DIREITOS NO BRASIL
}

Revista de Direitos Humanos e Efetividade Aprovado em: 09.12.2019

\author{
Allex Jordan Oliveira Mendonça ${ }^{1}$ \\ Glaucia Maria de Araujo Ribeiro ${ }^{2}$
}

\section{Resumo:}

O objetivo desta pesquisa é o de analisar o movimento do Novo Constitucionalismo LatinoAmericano, visando investigar se este fenômeno pode contribuir para políticas de proteção e de reconhecimento de direitos. A metodologia utilizada nesta pesquisa foi a do método dedutivo; quanto aos meios a pesquisa foi a bibliográfica, com uso da doutrina e da legislação; quanto aos fins, a pesquisa foi qualitativa. Concluiu-se que o Novo Constitucionalismo Latino - Americano pode contribuir para políticas de proteção e de reconhecimento de direitos no Brasil, embora hodiernamente o cenário brasileiro tenha se mostrado cheio de retrocessos.

Palavras-chave: Novo Constitucionalismo Latino-Americano; Neoconstitucionalismo; proteção de direitos; reconhecimento de direitos

\section{THE NEW LATIN AMERICAN CONSTITUTIONALISM AND ITS CONTRIBUTIONS IN POLICY OF PROTECTION AND RIGHTS RECOGNITION IN BRAZIL}

\begin{abstract}
:
The objective of this research is to analyze the movement of the New Latin American Constitutionalism being aimed at to investigate if this phenomenon can contribute for politics of protection and recognition of rights. The methodology used was of the deductive method; how much to the ways was the bibliographical with use of the doctrine and the legislation; how much to the ends the research was qualitative. It is concluded that the New Latin American Constitutionalism can contribute for protection politics and of recognition of rights in Brazil even so currently the Brazilian scene if has shown full of retrocessions.
\end{abstract}

Keywords: New Latin American Constitutionalism; Neoconstitutionalism; protection of rights recognition of rights

\footnotetext{
${ }^{1}$ Possui graduação em Direito pela Universidade do Estado do Amazonas (2015); Pós Graduação em Direito Público pela Universidade do Estado do Amazonas/ Ordem dos Advogados do Brasil - seção Amazonas (2017); Aluno especial do Mestrado em Direito Ambiental pela Universidade do Estado do Amazonas; Professor Voluntário em Direito Administrativo na Universidade do Estado do Amazonas (2017); Aluno do Mestrado em Direito Ambiental - Universidade do Estado do Amazonas (2018), Advogado. E-mail: allex.jom@ gmail.com

${ }^{2}$ Professora de Direito Administrativo da Universidade do Estado do Amazonas (UEA). Doutora em Saúde Coletiva pela Universidade do Estado do Rio de Janeiro (UERJ-2018). Mestre em Direito Ambiental pela Universidade do Estado do Amazonas - UEA (2004). Especialista em Administração Pública com ênfase em Direito Público. Advogada. Possui graduação em Filosofia pela Universidade Federal do Amazonas - UFAM (1981); Graduação em Direito pela Universidade Federal do Estado do Amazonas - UFAM (1984). glauciamariaribeiro@gmail.com
} 


\section{INTRODUÇÃO}

O Constitucionalismo na América Latina iniciou no final do século XX e seu estudo é voltado para a análise da limitação jurídica do poder estatal conjuntamente a preservação dos direitos fundamentais. Este fenômeno busca afirmar o documento constitucional como garantidora de direitos, colocando-a no mais alto grau de hierarquia das leis, consubstanciando em um verdadeiro movimento jurídico e político.

Do seu nascimento até hoje, o constitucionalismo na América Latina mudou consideravelmente em relação ao mesmo movimento vivido nos países no norte do globo, apresentando rupturas dos paradigmas europeus e buscando a verdadeira realidade latina. Neste sentido pesquisa se justifica pelo tratamento que o Novo Constitucionalismo dá as questões de políticas de proteção e de reconhecimento de direitos nos países latinos os quais o movimento está presente.

Primeiramente será feita uma abordagem a respeito do conceito de constitucionalismo e de sua evolução, até a chegada do Neoconstitucionalismo, na modernidade, para contrapor com os fundamentos que movimento social latino difunde. Neste tópico é observado que o constitucionalismo vivido na América latina até o inicio do século XX é dotado da característica da colonialidade, demonstrando um mimetismo jurídico- científico no que diz respeito à aplicação do ordenamento jurídico. No fim deste tópico é constatado que o neoconstitucionalismo é uma doutrina universalizante e homogênea, dificultando seu encaixe no âmbito de uma sociedade latina complexa, marcada por diferenças culturais, econômicas e sociais.

A América Latina como forma de se desligar deste processo de colonialidade, aliado aos problemas sócioambientais vívidos no final do século XX, apresentou novas constituintes

- Estados da Venezuela, Equador e Bolívia - na busca de reproduzir as necessidades de seus segmentos sociais majoritários, como povos indígenas, afro-americanos, campesinos e movimentos urbanos. Assim nasce o movimento do Novo Constitucionalismo andino. 
Após a apresentação do Novo Constitucionalismo Latino Americano, a qual demonstrará sua história, características e diferenças em relação ao neoconstitucionalismo, o segundo tópico tratará sobre o constitucionalismo vivido no Brasil, a fim de analisar se a Constituição Federal de 1988 apresenta características que convergem com o movimento latino-americano. Neste tópico é constatado que pelo constitucionalismo vivido pela Lei de 1988 ainda é possível observar que, mesmo com uma gama de direitos conquistados e expressos no texto constitucional, ainda há um atraso político e social, caracterizado pela

desigualdade de concentração de renda que afeta questões de educação, saúde, saneamento, moradia, cultura e meio ambiente.

Por fim, o terceiro tópico averigua a incidência do Novo Constitucionalismo LatinoAmericano no Brasil, visto que tal movimento busca diminuir a desigualdade social e econômica por meio da proteção de grupos sociais minoritários mais vulneráveis; além da adoção de um Estado Multicultural, garantindo a participação e o reconhecimento de todas as cosmovisões que formam a América Latina; adotando o conceito de "bem viver". Com isso será possível constatar possíveis avanços ou retrocessos no país em relação à proteção e reconhecimento de direitos, visto que diversas realidades sociais existem no Brasil e estão em desconformidade com o que é pregado pelo ordenamento constitucional vigente.

\section{ABORDAGEM DO NOVO CONSTITUCIONALISMO LATINO AMERICANO}

A compreensão do Novo Constitucionalismo Latino-Americano é tarefa dinâmica e ainda em construção. Trata-se de um movimento constitucional, fruto de lutas sociais que ainda estão ganhando vez e voz. Estes ensinamentos não foram criados dentro de um ambiente acadêmico e, para alguns autores, o Novo Constitucionalismo Latino-Americano não pode ser considerado ainda um modelo doutrinário - diferentemente do caso do Neoconstitucionalismo. (SILVA; NETO, p.69).

A melhor maneira de compreender o movimento do Novo Constitucionalismo Latino-Americano é fazendo uma abordagem do Constitucionalismo e de sua evolução, até a chegada do Neoconstitucionalismo, na modernidade, para contrapor com os fundamentos que movimento social latino difunde.

O constitucionalismo, para Godoy (2012, p.40), é um processo que busca afirmar a Constituição como garantidora de direito, opondo-se ao poderes ilimitados de quem está 
comandando uma nação, através do estabelecimento de parâmetros de atuação do poder.

Segundo Ferreira Filho (2012, p. 33) o constitucionalismo é conceito que alimenta o movimento jurídico e político de determinado país. MartonioMont'Alverne Barreto Lima (2012, p.120) conceitua o constitucionalismo como o "resultado do acúmulo teórico do estudo das constituições e de seu desenvolvimento na história. O constitucionalismo, desta forma, consiste também na investigação sobre as formas de organização política do poder do Estado a ser exercido".

Já Canotilho (2011, p.51) ensina o constitucionalismo como "uma técnica específica de limitação do poder com fins garantísiticos".

Dadas tais premissas, nota-se o constitucionalismo como um movimento ligado à limitação jurídica do poder e à preservação dos direitos fundamentais.

Quanto sua análise histórica, o constitucionalismo na América Latina é divido por Gargarella, Pádua e Guedes (2016) em três períodos. O primeiro lapso temporal diz respeito ao nascimento do constitucionalismo, através do compromisso firmado entre liberais e conservadores, durante o período de 1850 a 1910, na qual a maior parte dos países da América - Latina possuía constituições liberais-conservadoras.

Este período foi marcado pelo liberalismo e pelo conservadorismo que caracterizavam a política da região: sistema de pesos e contrapesos, tolerância religiosa e um modelo federalista centralizador de organização territorial baseados nas Constituições dos Estados Unidos e do Chile de 1833. Neste período, a proteção social e a participação popular não foram incorporadas nas constituições - este período caracteriza-se pela exclusão de parcela da população e pela ascensão de grupos radicais nas instituições públicas. Embora houvesse propostas constitucionais a respeito da questão social, o liberalismo-conservador que se justificava apenas na "ordem e progresso" impediu que tais políticas se efetivassem. (GARGARELLA; PÁDUA; GUEDES, 2016, p. 34)

A acentuada desigualdade social e crescimento da classe trabalhadora o liberalismoconservador, que caracterizou as constituições latinas, foi dando azo ao acontecimento político e social mais notável do século XX: a ruptura do Constitucionalismo Liberal através da Revolução Mexicana de 1910, fundamentada nos motivos transcritos alhures, culminou no nascimento da Constituição Mexicana de 1917, abrindo espaço para o Constitucionalismo Social (1910 a 1950). Embora o período tenha sido marcado pela promoção dos direitos sociais, a instauração de ditaduras na região latina e a adoção de reformas neoliberais 
causaram efeitos nas liberdades civis e políticas da população - assim, novas reformas constitucionais foram feitas para conceder proteção a direitos humanos básicos que foram saqueados durante os governos ditatoriais. (GARGARELLA; PÁDUA; GUEDES, 2016, p. 36).

Ressalta-se que o pós Segunda Guerra mundial (1939 a 1945) introduziu nos estudos constitucionais o conceito do neoconstitucionalismo - hodierna fase do direito constitucional. Nos anos de 1950 a 2010, por exemplo, a América - Latina inicia a promoção de diversos direitos humanos. Vale destacar o lapso temporal da evolução do constitucionalismo europeu em relação ao que ocorreu na América - Latina: enquanto que na Europa, o neoconstitucionalismo teve com marco histórico as Constituições da Alemanha de 1949, da Itália de 1947, de Portugal do ano de 1976 e da Constituição da Espanha de 1978, na América - Latina as mudanças constitucionais propagadas por esta nova doutrina podem ser visualizadas pelas Constituições do Brasil de 1988, da Colômbia em 1991, da Argentina em 1994, da Venezuela em 1999, do Equador em 2008, da Bolívia em 2009 e do México em 2011. Enquanto que na Europa, o final do século XX foi marcado pelo nascimento de uma nova perspectiva neoconstitucional, na América- Latina ocorreu o fim dos regimes ditatoriais latinos, marcados por reformas políticase econômicas de cunho neoliberal que provocaram, novamente, uma crise social e econômica, conforme aponta Gargarella, Pádua e Guedes (2016, p. 37).

Esta influência "atrasada" do neoconstitucionalismo na América - Latina é objeto de crítica do movimento do Novo Constitucionalismo Latino-Americano, inclusive, que tenta através de uma perspectiva decolonial demonstrar que os institutos que se aplicam na Europa não podem ser os mesmo aplicados na América Latina, visto tratar-se de outro continente, com outras perspectivas culturais. Vale destacar que a formação dos Estados Nacionais e do constitucionalismo da Europafoi marcada por violência e exclusão de parcela da populaçãoda América - Latina, que foi controlada pelas nações da península ibérica por muito tempo (desde o século XIV até as primeiras décadas do século XIX), conforme narra Barbosa e Teixeira (2017, p. 1155).

Esta dependência e controle são características da chamada "colonialidade", que se refere a um efeito da história e que se propaga até os dias atuais, através da padronização do poder que busca neutralizar hierarquias territoriais, de raça, cultura e de conhecimento científico. O Constitucionalismo, conhecimento científico que é, legitimou a padronização 
eurocêntrica coma exclusão de parte da população que era não era branca, européia e capitalista, baseando-se numa retórica universalista. (BARBOSA; TEIXEIRA, 2017, p. 1117).

Diante de tal quadro - caracterizado pela crise econômica e social - alguns países latinos voltaram-se para reformas sócio-legais, adotando documentos constitucionais mais robustos e garantidores no que se refere aos direitos sociais, econômicos e culturais, além do fortalecimento da soberania popular e da afirmação de estados multiculturais através do movimento do Novo Constitucionalismo Latino-Americano.

\begin{abstract}
As presentes constituições da América - Latina garantem a proteção do meio ambiente, cultura, saúde, educação, alimentação, moradia, trabalho, vestuário etc. Adicionalmente, algumas das Constituições novas ou reformadas incluíram garantias de equidade de gênero, incluíram mecanismos de democracia participativa, criaram as instituições do referendo popular ou da consulta popular, introduziram o direito à revogação do mandato (recall), ou reconheceram o direito das ações afirmativas. (GARGARELLA; PÁDUA; GUEDES, 2016, p. 38).
\end{abstract}

Feitas estas considerações históricas a respeito do Constitucionalismo LatinoAmericano, merece destaque, neste momento, tratar das características do constitucionalismo contemporâneo - alcunhado de neoconstitucionalismo - para contrapô-lo ao movimento que vem se desenvolvendo nos países latinos. Esta doutrina tem origem nos países do norte do globo, sendo caracterizada, a partir do final do século XX, no pós Segunda Guerra Mundial, como solução para os problemas que regimes totalitários resultaram.

Barbosa e Teixeira (2017, p. 1120) ensinam que esta doutrina européia busca uma nova composição dos preceitos do constitucionalismo a partir da idéia de que os documentos constitucionais são dotados de valores que sistematizam o caráter jurídico-normativo, o qual deve ser voltado a proteção da condição humana. Tem como característica também a aproximação do direito e da moral, sendo a Constituição o documento orientador da política; além disso, delega ao Judiciário a solução de conflitos de interesse de toda a sociedade, outorgando aos interpretes e aplicadores da lei a tarefa de decisão. Os autores ainda ensinam que o neoconstitucionalismo tem como característica a invasão de competências em relação ao controle de políticas públicas através do Judiciário. Além de uma teoria do direito, é considerado teoria de poder. É teoria de poder porque os juízes, utilizando-se da interpretação, podem atuar ora como legislador negativo e ora como legislador positivo.

É considerado teoria do direito porque se fundamenta numa dimensão que penetra 
em todos os ramos do direito, através do fenômeno da Constitucionalização - movimento que possui efeitos que afetam todo o sistema jurídico; efeitos que expandem as normas constitucionais de forma que seu conteúdo material e valorativo ganha força normativa em todos os campos da ciência jurídica.

A consequiência deste movimento é o condicionamento e a valoração de todas as normas de direito infraconstitucional, que passam a orbitar os valores, fins públicos e princípios contemplados na Constituição. Tal efeito reverbera na atividade de todas as funções do Estado, nas relações que estas funções possuem com os particulares e também na relação mútua entre particulares. (BARROSO, 2012, p. 32).

O fato de o Neoconstitucionalismo ser uma doutrina universalizante e homogênea reproduzindo a colonialidade - faz com que esta doutrina não tenha capacidade de lidar com o diferente, havendo dificuldade em se encaixar no âmbito de uma sociedade complexa, marcada por diferenças culturais, econômicas, sociais e políticas. Destaca-se esta crítica:

O neoconstitucionalismo europeu não tem se mostrado capaz de lidar com as diferenças, sejam elas econômicas, culturais, de crença, raciais e de gênero, dentre tantas outras. Sob certo sentido, a ideia de cidadania representou um meio relativamente eficiente de lidar com a diferença. A construção discursiva em torno do referencial da cidadania representa um eficiente meio para permitir a convivência entre diferentes, já que permite a separação do âmbito privado (onde as pessoas podem ser diferentes em suas crenças, convicções, etc.) do âmbito público (onde as pessoas devem ser iguais, já que cidadãos). (BARBOSA; TEIXEIRA, 2017, p. 1123).

Por fim, os autores em comento apresentam didaticamente as principais características do neoconstitucionalismo. Vejamos:

\footnotetext{
São características do neoconstitucionalismo europeu: a) reconhecimento de um amplo catálogo de direitos fundamentais; b) afirmação da força normativa da Constituição; c) ampliação do poder jurisdicional sobre o poder legislativo; c) afirmação de técnicas ponderativas voltadas para a interpretação e aplicação do direito; d) afirmação do direito em uma dimensão principiológica. (BARBOSA; TEIXEIRA, 2017, p. 1121).
}

Como dito anteriormente, a América - Latina, no final do século XX, nos anos 80, foi marcada pelo fim dos regimes militares e autoritários. O constitucionalismo andino, conforme identifica Barbosa e Teixeira (2017, p. 1125) assemelha-se ao europeu, a partir de um mimetismo teóricoque foi vivido anteriormente pelos países do norte do globo. Este período foi marcado pela redemocratização e proteção das liberdades individuais e dos 
direitos sociais, e pelo fortalecimento dos direitos humanos - sem nenhuma característica de ruptura com o padrão eurocêntrico. Tal mimetismo excluiu o reconhecimento de uma pluralidade étnica, racial e religiosa característicos de cosmovisões de países latinos.

Tento em vista os problemas sociais e políticos vividos na América - Latina, ao final dos anos 90, alguns Estados deste território, como Venezuela, Equador e Bolívia, apresentaram novas constituintes que resguardaram a participação popular e a diversidade nacional, através de uma ruptura da característica universalista do mundo moderno - assim encarna o Novo Constitucionalismo Latino, movimento que ocorreu em razão dos movimentos sociais e da ascensão dos partidos políticos de esquerda. (BARBOSA; TEIXEIRA, 2017, p. 1127).

Diferentemente do neoconstitucionalismo, que se preocupa apenas com a dimensão jurídica da Constituição, o Novo Constitucionalismo, busca a legitimidade democrática, de forma que a soberania popular possa determinar a geração ou alteração de normas constitucionais.

\footnotetext{
Por su parte, el NUEVO CONSTITUCIONALISMO asume las posiciones del neoconstitucionalismo sobre la necesaria impregnación constitucional del ordenamiento jurídico pero su preocupación no es sólo la dimensión jurídica de la Constitución sino, en um primer orden, su legitimidad democrática. En efecto, si el constitucionalismo es el mecanismo por el que la ciudadanía determina y limita el poder público, el primer problema del constitucionalismo debe ser garantizar la traslación fiel de la voluntad del poder constituyente (del pueblo) y certificar que solo la soberanía popular, directamente ejercida, pueda determinar la generación o la alteración de las normas constitucionales.(DALMAU, 2008, p. 18).
}

Ato contínuo, Daumau (2008, p. 19) argumenta que o Novo Constitucionalismo Latino-Americano defende que o conteúdo das cartas constitucionais deve gerar mecanismos de participação política direta dos cidadãos, além de garantir os direitos fundamentais, incluídos os direitos sociais, econômicos e culturais. O autor em comento ensina que o Novo Constitucionalismo Latino Americano possui características formais e materiais.

Há quatro características formais que encampam este movimento: seu conteúdo inovador (originalidade); sua extensão de articulação (amplitude); a capacidade de agregar elementos tecnicamente complexos através de uma linguagem acessível (complexidade); e por fim, o fato de que o movimento está comprometido com a legitimação do poder constituinte do povo antes de qualquer mudança constitucional (rigidez).

Como características de cunho material, o movimento latino possui o compromisso 
de buscar instrumentos que recomponham a relação perdida, ou nunca alcançada, entre soberania popular e governo, através de uma democracia participativa; e tem a necessidade de romper com os sistemas constitucionais anteriores, apresentando uma nova carta de direitos preocupados com a individualização e coletivização de seu povo.

As Constituições da Venezuela de 1999, do Equador de 2008 e da Bolívia de 2009 são os exemplos de documentos que disseminam o viés do Novo Constitucionalismo, buscando ruptura com a colonialidade eurocêntrica, além do fortalecimento de instrumentos de participação popular, que embora conhecidos, não era utilizados. Com o fortalecimento político da população, o Novo Constitucionalismo Latino-Americano se volta para a proteção de grupos sociais minoritários mais vulneráveis, como mulheres, índios e negros, invocando a características de um Estado Plurinacional ${ }^{3}$, Pluriético, Multicultural; adotando o conceito de "bem viver", o qual busca situar o ser humano como parte integrante da natureza; inserindo a linguagem de gênero nos documentos constitucionais; garantindo a participação e reconhecimento de todas as cosmovisões que formam a América - Latina; buscando a superação das desigualdades sociais e econômicas, além de estabelecer uma hierarquia constitucional no ordenamento jurídico. (BARBOSA; TEIXEIRA, 2017, p. 1128).

Ressalta-se o conceito de "bem viver" adotado por este movimento: o antropocentrismo vai dando lugar ao ecocentrismo, visão que centraliza os direitos da Terra, comproteção e respeito à biodiversidade. Exemplo disso é a Constituição do Equador, na qual a noção de buenvivir reforça e guia os princípios e regras do documento constitucional deste país. Segundo Neto e Araújo (2014, p.381), o conceito de bem viver revela a nova opção político-jurídica dos países latinos, que buscam romper com a tradicional teoria constitucional européia, buscando o reconhecimento dos direitos dos povos e comunidades tradicionais andinas $^{4}$ (direito a identidade cultural); além de refundar o Estado, através de uma perspectiva constitucional ecocêntrica ${ }^{5}$, de modo que a inserção deste conceito no ordenamento jurídico

\footnotetext{
${ }^{3}$ A Constituição boliviana consagra a diversidade étnica, buscando proteger e promover a vida humana e não humana a partir dos movimentos sociais. Nomeada como Constituição Política Plurinacional Comunitária e Autônima do Estado da Bolívia, em seu preâmbulo exacerba que o Estado colonial, republicano e neoliberal fica no passado histórico. (BOLÍVIA, 2009).

${ }^{4}$ Neto e Araújo (2014) abordam nesta pesquisa científica, intitulada "Buenvivir": notas de um conceito constitucional em disputa, a proteção do conhecimento tradicional associado à biodiversidade na Bolívia e no Equador. Importante destacar que uma das características fundamentais que a Constituição equatoriana trouxe foi a ligação que o conhecimento científico possui com o conhecimento ancestral, superando o monismo científico e a colonização do saber, que antes eram dependentes dos países de norte.

${ }^{5}$ A biodiversidade possui seção específica na Constituição do Equador, de forma que o bem viver conduz a edição dos princípios ambientais.
} 
muda o tratamento dado ao meio ambiente e a natureza(Pachamama) ${ }^{6}$ passa a ser sujeito de direito.

Os autores ainda chamam atenção para o fato de que o buenvivir ainda não é uma noção clara, pois se trata de um processo social em desenvolvimento.Notadamente, a partir do conceito de bem viver a Constituição do Equador reconhece a diversidade como um princípio fundador de uma país pluriétnico e multireligioso, ainda que laico ${ }^{7}$.

\begin{abstract}
Mas, afinal, que é o buenvivir? Mais: o que vem a ser antes de tornar-se texto constitucional, decisão política fundamental dos grupos sociais equatorianos? O buenvivirconsiste num conjunto de conhecimentos e saberes indígenas ancestrais (cosmovisão andina) que permite estabelecer uma relação harmoniosa com a natureza (Pachamama) - ente que possui direitos na constituição equatoriana de Montecristi.(NETO; ARAÚJO,2014, p. 387).
\end{abstract}

Destaca-se também a característica de plurinacionalidade como resposta a exclusão e marginalização vivida pelos que eram diferentes do padrão eurocêntrico; que reconhece cosmovisões e as positiva; insere jurisdições indígenas legítimas, fortalece e empodera a cidadania e os instrumentos de democracia ${ }^{8}$ direta, facilitando que grupos sociais vulneráveis participem das tomadas de decisões políticas.

Segundo Neto e Araújo (2014, p. 392) a educação também passa a ser ferramenta necessária para a edição do ordenamento jurídico equatoriano baseado no buenvivir, de forma

\footnotetext{
${ }^{6}$ Tolentino e Oliveira (2015) em pesquisa intitulada "Pachamama e o Direito à vida: uma reflexão na perspectiva do novo Constitucionalismo Latino-Americano" apresenta uma reflexão a respeito da natureza a partir do movimento do constitucionalismo andino, que passa a ser sujeito de direitos pelas Constituições da Bolívia e do Equador. Os autores denotam que a expressão vem de mito andino que se refere ao "tempo". Entretanto, no decorrer dos anos, com a modificação da linguagem, o vocábulo passou a significar Terra.

${ }^{7}$ No preâmbulo da Constituição do Equador, por exemplo, resta claro o reconhecimento da diversidade como princípio fundante da ordem política:

RECONOCIENDO nuestras raíces milenarias, forjadas por mujeres y hombres de distintos pueblos, CELEBRANDO a la naturaleza, la Pacha Mama, de la que somos parte y que es vital para nuestra existencia, INVOCANDO el nombre de Dios y reconociendo nuestras diversas formas de religiosidad y espiritualidad, APELANDO a la sabiduría de todas las culturas que nos enriquecen como sociedad, COMO HEREDEROS de las luchas sociales de liberación frente a todas las formas de dominación y colonialismo, Y con un profundo compromiso con el presente y el futuro, Decidimos construir Una nueva forma de convivencia ciudadana, en diversidad y armonía con la naturaleza, para alcanzar el buen vivir, el sumak kawsay; Una sociedad que respeta, en todas sus dimensiones, la dignidad de las personas y las colectividades; Un país democrático, comprometido con la integración latinoamericana - sueño de Bolívar y Alfaro-, la paz y la solidaridad con todos los pueblos de la tierra; y, En ejercicio de nuestra soberanía, en Ciudad Alfaro,Montecristi, provincia de Manabí, nos damos la presente. (EQUADOR, 2008).

${ }^{8}$ A relação que o neoconstitucionalismo tem com a democracia é alvo de crítica para Barbosa e Teixeira (2017, p. 1123), visto que enquanto esta corresponde a um processo de tomadas de decisões a partir da participação política da população, aquele, no que tange as questões sensíveis, busca solucionar as decisões por meio das Cortes Constitucionais, que assumem o papel de legislador, rompendo, assim, a idéia da decisão a partir da vontade das maiorias.
} 
que prepare sua população a partir de uma visão holistica do mundo ${ }^{9}$.

Sem esforço, percebe-se que o Novo Constitucionalismo Latino-Americano busca contribuir com o debate democrático através de políticas que promovem o reconhecimento dos direitos de igualdade e diferença, empoderando as minorias sociais, possibilitando novas formar de pensar a organização de um Estado nacional soberano, preocupando-se também com a diversidade ambiental pautada na concepção de "bem-viver" e exaltando e valorizando a excepcional história do continente.

O novo constitucionalismo andino busca suprir a inaptidão de um sistema constitucional que não promove a proteção dos mais vulneráveis e excluídos, e prioriza a natureza como instrumento de garantia do direito a vida.

Após a apresentação do Novo Constitucionalismo Latino Americano, a qual demonstrou sua história, características e diferenças em relação ao neoconstitucionalismo, buscará, neste ponto, abordar o constitucionalismo vivido no Brasil, a fim de analisar se a Constituição Federal de 1988 apresenta características que convergem com o movimento latino. Por fim, nesta parte não será abordado o estudo de todas as Constituições brasileiras, atendo-se apenas ao documento constitucional vigente.

$\mathrm{O}$ constitucionalismo democrático foi a ideologia vitoriosa do século $\mathrm{XX}$. O imaginário social contemporâneo vislumbra nesse arranjo institucional, que procura combinar Estado de direito (supremacia da lei, ruleofthelaw, Rechtsstaat) e soberania popular, a melhor forma de realizar os anseios da modernidade: poder limitado, dignidade da pessoa humana, direitos fundamentais, justiça social, tolerância e - quem sabe? - até felicidade. (BARROSO, 2008, p.14).

Porém, não deixemos de falar que o constitucionalismo brasileiro percorreu historicamente um longo caminho - de um império autoritário, com a carta outorgada de 1824 até a formação e um Estado Constitucional Democrático, com a promulgação da Constituição Federal de 1988, tivemos oito constituições brasileiras. Do regime escravocrata vivido na vigência da constituição de 1824 herdamos o preconceito, a discriminação racial, cultural e étnica, com a conseqüente exclusão social, além do autoritarismo e patrimonialismo que até

\footnotetext{
${ }^{9} \mathrm{O}$ artigo 27 da Constituição Equatoriana prescreve: "La educación se centrará en el ser humano y garantizará su desarrollo holístico, en el marco del respeto a los derechos humanos, al medio ambiente sustentable y a la democracia; será participativa, obligatoria, intercultural, democrática, incluyente y diversa, de calidad y calidez; impulsará la equidad de género, la justicia, la solidaridad y la paz; estimulará el sentido crítico, el arte y la cultura física, la iniciativa individual y comunitaria, y el desarrollo de competencias y capacidades para crear y trabajar. La educación es indispensable para el conocimiento, el ejercicio de los derechos y la construcción de un país soberano, y constituye um eje estratégico para el desarrollo nacional".
} 
hoje caracterizam, ainda, o estado brasileiro. No percurso do autoritarismo imperial ao Estado democrático de Direito ainda ocorreram longos episódios de restrição de direitos - marcado por um período ditatorial que expurgou qualquer vestígio de soberania popular e proteção aos direitos humanos.

A chegada da Constituição de 1988 representou, segundo Barroso (2008, p. 6), a passagem de um Estado autoritário para um Estado democrático de direito, apresentando alguns avanços que o constitucionalismo brasileiro conquistou: o fortalecimento dos direitos fundamentais e a centralidade da dignidade da pessoa humana em vários ramos do ordenamento jurídico; quanto aos direitos individuais, conquistaram-se as liberdades públicas (de expressão, de reunião, de associação) além da incorporação de direitos que no período ditatorial foram dizimados, como o direito ao devido processo legal e a presunção de inocência.

$\mathrm{Na}$ questão dos direitos sociais, o autor afirma que esta "têm enfrentado trajetória mais acidentada, sendo sua efetivação um dos tormentos da doutrina e da jurisprudência." (BARROSO, 2008, p. 8).

Isto porque o Brasil ainda é marcado pela exclusão social, com a privação de direitos econômicos e sociais, até a insuficiência de direitos mais básicos, negando-se a negros, índios e mulheres, não só a igualdade, mas como também a liberdade. Sem embargo, o autor reitera o avanço social no que diz respeito à universalização do acesso à educação - embora precária - além da evolução dos direitos coletivos e difusos, com a proteção do consumidor e do meio ambiente.

Embora a soberania popular tenha sido exaltada durante o período da constituinte, demonstrando um incontestável caráter democrático, o texto final expressa "uma vasta mistura de reivindicações legítimas de trabalhadores e categorias econômicas, cumulados com interesses cartoriais, reservas de mercado e ambições pessoais.” (BARROSO, 2008, p. 9).

A Constituição Federal de 1988 ainda reorganizou a federação como mecanismo de repartição do poder político, que no período ditatorial era concentrada em atribuições do Governo Federal, reduzindo o desequilíbrio que ocorria entre os Poderes da República; na economia buscou estabelecer o principado da livre iniciativa e da valorização do trabalho. Entretanto, ainda é possível observar um atraso político e social, caracterizado pela desigualdade de concentração de renda que afeta questões de educação, saúde, saneamento, moradia, cultura e meio ambiente. 
Do ponto de vista do avanço do processo civilizatório, também estamos para trás, com índices inaceitáveis de corrupção, deficiências nos serviços públicos em geral dos quais dependem, sobretudo, os mais pobres - e patamares de violência que se equiparam aos de países em guerra42. Por outro lado, o regime de 1988 não foi capaz de conter a crônica voracidade fiscal do Estado brasileiro, um dos mais onerosos do mundo para o cidadão-contribuinte. Sem mencionar que o sistema tributário constitui um cipoal de tributos que se superpõem, cuja complexidade exige a manutenção de estruturas administrativas igualmente custosas. (BARROSO, 2008, p. 13).

Aliado a estes problemas, o sistema político ainda é marcado por corrupção e violência, enfraquecendo ainda mais o exercício da cidadania e desconectando a sociedade do Estado. Vale destacar:

\begin{abstract}
No conjunto de desacertos das últimas duas décadas, a política passou a ser um fim em si mesma, um mundo à parte, desconectado da sociedade, visto ora com indiferença, ora com desconfiança. As repetidas crises produzidas pelas disfunções do financiamento eleitoral, pelas relações oblíquas entre Executivo e parlamentares, bem como pelo exercício de cargos públicos para benefício próprio têm trazido, ao longo dos anos, uma onda de ceticismo que abate a cidadania e compromete sua capacidade de indignação e de reação. A verdade, contudo, é que não há Estado democrático sem atividade política intensa e saudável, nem tampouco sem parlamento atuante e investido de credibilidade. É preciso, portanto, reconstruir o conteúdo e a imagem dos partidos e do Congresso, assim como exaltar a dignidade da política. O sistema político brasileiro, por vicissitudes diversas, tem desempenhado um papel oposto ao que lhe cabe: exacerba os defeitos e não deixa florescer as virtudes. (BARROSO, 2008, p.13)
\end{abstract}

Não obstante, o Brasil é caracterizado por um constitucionalismo democrático, que significa um poder limitado que preserva os direitos fundamentais, além de traduzir a idéia de soberania popular. Nas ultimas décadas, como falado no primeiro tópico, o direito constitucional passou por um conjunto de transformações que alcunharam como neoconstitucionalismo. Barroso (2014, p. 6) afirma que esta nova fórmula do constitucionalismo é marcada pela força normativa das normas constitucionais, que se tornaram fonte de direitos e obrigações; reconhecendo o Direito Constitucional como objeto próprio e autônomo; e contribui para a ascensão do Poder Judiciário, que cuida da tarefa de concretizar direitos e valores constitucionais.

A Constituição Federal de 1988 e o processo de redemocratização, pós-ditadura, são o marco histórico ${ }^{10}$ do novo Direito Constitucional no Brasil. Vale ressaltar que este

10 Barroso (2014, p.7) apresenta três marcos fundamentais de transformação do Direito Constitucional Contemporâneo. O marco histórico, caracterizado na Europa, pós-guerra, com as Constituições da Alemanha e 
constitucionalismo democrático fundamenta-se na dignidade da pessoa humana, considerado um valor fundamental e assumindo a feição de princípio constitucional, podendo ser visualizado como um valor intrínseco a todos os seres humanos, que diz respeito à autonomia de cada indivíduo e limitada legitimamente em nome de valores sociais ou interesses estatais. (BARROSO, 2014, p. 20).

Sarmento (2008) apresenta sinteticamente os fenômenos que se desenvolvem na égide da Constituição Federal de 1988 e que consagram as mudanças trazidas pelo paradigma do neoconstitucionalismo:

\begin{abstract}
(a) reconhecimento da força normativa dos princípios jurídicos e valorização da sua importância no processo de aplicação do Direito; (b) rejeição ao formalismo e recurso mais freqüente a métodos ou "estilos" mais abertos de raciocínio jurídico: ponderação, tópica, teorias da argumentação etc.; (c) constitucionalização do Direito, com a irradiação das normas e valores constitucionais, sobretudo os relacionados aos direitos fundamentais, para todos os ramos do ordenamento; (d) reaproximação entre o Direito e a Moral, com a penetração cada vez maior da Filosofia nos debates jurídicos; e (e) judicialização da política e das relações sociais, com um significativo deslocamento de poder da esfera do Legislativo e do Executivo para o Poder Judiciário. (SARMENTO, 2008, p. 1).
\end{abstract}

Já Barcelos (2005, p. 84) ordena as características do neoconstitucionalismo em dois grupos: os elementos materiais; e os elementos metodológico-formais. Este primeiro diz respeito às premissas fundamentais de um sistema jurídico moderno: o reconhecimento da normatividade da carta constitucional, dotada de imperatividade; a supremacia da Constituição; e a centralidade deste documento nos ordenamentos jurídicos, de forma que todos os ramos do direito devem ser interpretados conforme os mandamentos constitucionais.

Já o grupo dos elementos materiais diz respeito ao fato de que a Constituição é marcada por valores e opções políticas; e pela expansão de conflitos entre as opções normativas e filosóficas existentes no ordenamento jurídico. Isso porque após a Segunda Guerra Mundial, neoconstitucionalismo foi marcado pela introdução de valores ou opções políticas nos textos das constituições, que são voltados à promoção da dignidade humana e aos direitos fundamentais - este elemento material é justificado como uma reação ao que foi vivido nos regimes políticos ditatoriais e autoritários do século XX.A expansão destes conflitos se deve pelo fato de que os direitos fundamentais não podem ser hierarquizados em

da Itália. O marco filosófico, caracterizado pelo pós-positivismo, que reconhece que a aplicação do direito é influenciada pela moral e pela política e, por fim, o marco teórico caracterizado pelo reconhecimento de força normativa do documento constitucional, além da expansão da jurisdição constitucional e a evolução da hermenêutica jurídica com a nova interpretação constitucional. 
abstrato. (BARCELOS, 2008, p. 87).

Em qualquer caso, a promoção e a proteção dos direitos fundamentais são feitas por meio de políticas públicas, exigindo omissão ou ações do Estado, o qual está obrigado a realizar os fins que constam na Constituição, tendo em vista a introdução de valores e opções políticas que constam neste documento. Os direitos fundamentais estão consagrados como cláusulas pétreas no art. 60, $\S 4^{\circ}$, IV da Constituição Federal, devendo o Poder Público submeter-se a este mandamento, visto que estes direitos constituem parte essencial, devendo ser observados por qualquer grupo político no poder. Além disso, a promoção de tais normasé indispensável para o funcionamento da democracia.

Desta feita, diante da Constituição, as políticas públicas que promovem e protegem os direitos fundamentais não podem sofrer retrocesso, pois constituem um existencial mínimo de necessidades básicas de um indivíduo.

\section{A INCIDENCIA DO MOVIMENTO DO NOVO CONSTITUCIONALISMO LATINO AMERICANO NO BRASIL: AVANÇOS E/OU RETROCESSOS}

Tendo em vista que o movimento do Novo Constitucionalismo Latino Americano busca diminuir a desigualdade social e econômica por meio da proteção de grupos sociais minoritários mais vulneráveis; além da adoção de um Estado Multicultural, garantindo a participação e o reconhecimento de todas as cosmovisões que formam a América Latina; adotando o conceito de "bem viver", a terceira parte deste trabalho buscará averiguar se o ordenamento jurídico brasileiro atende tais premissas, para identificar possíveis avanços ou retrocessos no país em relação proteção e reconhecimento de direitos.

Inegavelmente, diversas realidades sociais existem no Brasil e estão em desconformidade com o que é pregado pelo ordenamento constitucional, embora a dignidade da pessoa humana e a redução das desigualdades sociais sejam, respectivamente, princípios estruturantes e objetivos da nação. Aliado a isso, atualmente, grande parte dos problemas socioambientais são minimizados pelo discurso do Presidente da República do Brasil no qual é noticiado em episódios de racismo $^{11}$, xenofobia ${ }^{12}$, misoginia ${ }^{13}$, guerra aos direitos

\footnotetext{
${ }^{11}$ PGR denuncia Jair Bolsonaro por racismo e Eduardo Bolsonaro por ameaças a jornalista. Disponível em http://www.mpf.mp.br/pgr/noticias-pgr/pgr-denuncia-jair-bolsonaro-por-racismo-e-eduardo-bolsonaro-porameacas-a-jornalista. Acesso em 05 de agosto de 2019.
} 
humanos ${ }^{14}$, cortes na ciência ${ }^{15}$, relativização do trabalho infantil ${ }^{16}$ e da pobreza ${ }^{17}$ e destruição do meio ambiente, o que aflige e limita a propagação dos direzes do Novo Constitucionalismo andino.

Apesar disso, Oliveira e Streck (2012, p. 21) sinalizam que há um direcionamento do Estado brasileiro ao dizeres do constitucionalismo andino, visto que possui elementos equivalentes, como o presidencialismo, o Estado Democrático, além do pluralismo como fundamento da República. O neoconstitucionalismo promove a dignidade humana e os direitos fundamentais, o fato de ser uma doutrina universalizante e homogênea - como dito alhures - faz com que esta não tenha capacidade de lidar com o diferente, havendo dificuldade em se encaixar no âmbito de uma sociedade esculpida por diferenças culturais, econômicas, sociais e políticas.

Já os países que pregam pelo novo movimento constitucional andino buscam uma trazer de volta a ligação que o conhecimento científico possui com o conhecimento ancestral, superando o monismo científico e a colonização do saber, que antes eram dependentes dos países de norte, o que mostra grande respeito às comunidades tradicionais e indígenas da região. Busca também refundar o Estado como sendo Pluriétnico - inserindo jurisdição indígena, apta a julgar casos que envolvam cosmovisões exclusivas da região - o neoconstitucionalismobrasileiro é marcado pelo protagonismo do Poder Judiciário ${ }^{18}$, que julga

12 AZEVEDO, RITA. Setembro de 2015: Bolsonaro chama refugiados de "escória do mundo". Disponível em https://exame.abril.com.br/brasil/bolsonaro-chama-refugiados-de-escoria-do-mundo/. Acesso em 05 de agosto de 2019.

${ }^{13}$ LÁZARO. Natália; MACEDO, Isabella. Bolsonaro faz piada sobre ser "misógino" e relembra que é réu no STF. Disponível em https://www.metropoles.com/brasil/politica-br/bolsonaro-faz-piada-sobre-ser-misogino-erelembra-que-e-reu-no-stf. Acesso em 05 de agosto de 2019.

${ }^{14}$ A flexibilização da regulação sobre o porte e a posse de armas, que pode contribuir com o aumento do número de homicídios no Brasil; A nova política nacional sobre drogas, que eleva o caráter punitivo de tais políticas e atenta contra o direito à saúde e o discurso sobre diretos de povos indígenas e quilombolas são exemplos de guerra aos direitos humanos. Ver mais em: Discurso da administração de Bolsonaro contra direitos humanos começa a se concretizar em medidas nos primeiros meses de governo. Disponível em https://anistia.org.br/noticias/discurso-da-administracao-de-bolsonaro-contra-direitos-humanos-comeca-seconcretizar-em-medidas-nos-primeiros-meses-de-governo/. Acesso em 05 de agosto de 2019.

${ }^{15}$ COELHO, Gabriela. Presidente do TRF-1 derruba liminar que suspensdeucortes na Educação. Disponível em https://www.conjur.com.br/2019-jun-12/presidente-trf-derruba-suspensao-cortes-educacao. Acesso em $05 \mathrm{de}$ agosto de 2019.

16 Bolsonaro defende trabalho infantil: "não prejudica as crianças". Disponível em https://exame.abril.com.br/brasil/em-live-bolsonaro-afirma-que-trabalho-nao-atrapalha-criancas/. Acesso em 05 de agosto de 2019.

${ }^{17}$ Bolsonaro: "Falar que se passa fome no Brasil é uma grande mentira, é um discurso populista". Disponível em https://brasil.elpais.com/brasil/2019/07/19/politica/1563547685_513257.html. Acesso em 05 de agosto de 2019.

${ }^{18}$ A maioria dos membros do Poder Judiciário é formada por homens, brancos, católicos, casados e com filhos, conforme pesquisa do CNJ sobre o perfil sociodemográfico dos magistrados brasileiros de 2018. O que, por vezes, pode reproduzir os efeitos de uma colonialidadeuniversalizante e homogênea, sem que haja a devida 
todas as questões sensíveis envolvendo reconhecimento e proteção de direitos de minorias.

O movimento latino possui o compromisso de buscar instrumentos que recomponham a relação perdida, ou nunca alcançada, entre soberania popular e governo, através de uma democracia participativa e direta e tem a necessidade de romper com os sistemas constitucionais anteriores, apresentando uma nova carta de direitos preocupados com a individualização e coletivização de seu povo. Para mais, o novo constitucionalismo andino se volta para a proteção de grupos sociais minoritários mais vulneráveis (mulheres, índios e negros) invocando a características de um Estado Plurinacional ${ }^{19}$, Pluriético e Multicultural, dando lugar de destaque para as comunidades tradicionais e indíginas. (OLIVEIRA; STRECK, 2012, p. 16)

Adotando o conceito de "bem viver", o movimento andino busca situar o ser humano como parte integrante da natureza; inserindo a linguagem de gênero nos documentos constitucionais $^{20}$; garantindo a participação e reconhecimento de todas as cosmovisões que formam a América - Latina; inclusive a valorização do direito internacional e comunitário $^{21}$,buscando a superação das desigualdades sociais e econômicas, além de estabelecer uma hierarquia constitucional no ordenamento jurídico.

Wolkmer (2011, p. 152) afirma que no caso brasileiro a Constituição Federal, em seu art. 131 mostra evidente o entendimento nitidamente pluralista e multicultural quando o documento afirma que "são reconhecidos aos índios sua organização social, costumes, línguas, crenças e tradições, e os direitos originários sobre as terras que tradicionalmente ocupam, competindo à União demarcá-las, proteger e fazer respeitar todos os seus bens".

Aliado aos problemas socioambientais, o neoconstitucionalismo brasileiro ignora a atuação do legislador ordinário, pois impõe força normativa imediata a Constituição, criando um grande espaço que separa os cidadãos das decisões deliberativas infraconstitucionais,

sensibilidade para os casos que envolvam negros, índios, mulheres ou outra minoria. Sobre o tema, v. CONSELHO NACIONAL DE JUSTIA. Perfil Sociodemográfico dos Magistrados Brasileiros 2018. Disponível em https://www.conjur.com.br/2018-set-13/maioria-judiciario-homens-brancos-casados-mostra-pesquisa. Acesso em 31 de agosto de 2019.

${ }^{19}$ A Constituição boliviana consagra a diversidade étnica, buscando proteger e promover a vida humana e não humana a partir dos movimentos sociais. Nomeada como Constituição Política Plurinacional Comunitária e Autônima do Estado da Bolívia, em seu preâmbulo exacerbam que o Estado colonial, republicano e neoliberal fica no passado histórico. (BOLÍVIA, 2009).

${ }^{20}$ A constituição Equatoriana, em seu preâmbulo reconhece que o povo soberano do Equador é formado por mulheres e homens de distintonspovos. (EQUADOR, 2008).

${ }^{21}$ A Constituição da Colômbia dispõe que os tratados de direitos humanos possuem posição preferencial em relação a hierarquia constitucional. Assim como a Constituição da Bolívia que dispõe que esta será interpretada conforme os tratados internacionais de direitos humanos ratificados pelo país. 
deixando a cargo do Poder Judiciário a resolução de variadas questões envolvendo dignidade humana e direitos fundamentais, fato que vai de encontro com o que é ensinado pelo constitucionalismo andino, o qual prega a participação popular e a diversidade nacional.

\begin{abstract}
O papel menor conferido à legislação ordinária dá a exata dimensão do aparente desprezo dos neoconstitucionalistas pelos poderes democraticamente legitimados. Se tudo pode ser resolvido a partir de uma interpretação direta da Constituição, de que valem as normas aprovadas pelo Poder Legislativo? Ou, mais especificamente, se as opções político-legislativas do legislador encontram-se "amarradas" pela Constituição Federal de 1988, por que não submeter ao Poder Judiciário toda e qualquer decisão de natureza política? (MONTEIRO, 2017, p. 59).
\end{abstract}

Em relação à questão ecológica, o Brasil, através Constituição Federal de 1988, em seu artigo 255, exalta a proteção do meio ambiente por meio da sociedade e do Estado, que devem obrigatoriamente garantir um meio ambiente ecologicamente equilibrado. Tolentino e Oliveira (2015, p. 331) afirmam que o documento constitucional brasileiro, assim como a legislação infraconstitucional, protege o meio ambiente apenas para preservá-lo, sendo interpretado com fornecedor de vida e de recursos ao homem, remontando uma concepção utilitarista e antropocêntrica da natureza. A biodiversidade passa a ser sujeito de direitos pelas Constituições da Bolívia e do Equador ${ }^{22}$, demonstrando a evolução da concepção utilitarista e antropocêntrica para dar espaço a uma visão ecocêntrica, centralizando os direitos da Terra, com proteção e respeito à biodiversidade. Exemplo disso é que a Constituição do Equador possui seção específica a respeito do meio ambiente, de forma que o bem viver conduz a edição dos princípios ambientais - enquanto que os alimentostransgênicos são proibidos no Equador, fundamentado no art. 401 da sua Constituição, no Brasil a trajetória dos transgênicos é de ascensão ${ }^{23}$.

Embora não haja grande incidência do movimento do Novo Constitucionalismo Latino-Americano no Brasil, a Constituição, em tese, reconhece alguns dos novos direitos como direitos humanos, direitos dos povos indígenas, direito da criança e do adolescente, do idoso e do meio ambiente - resultante de lutas sociais; esta carta constitucional"talvez se ajuste bem como exemplo de um constitucionalismo de transição, como alguns preferem

\footnotetext{
${ }^{22}$ A Constituição da Bolívia prevê direitos dos animais e a Constituição equatorianaprevê direitos da Natureza e prevê, explicitamente, direitos para além da espécie humana.

${ }^{23} \mathrm{O}$ presidente Jair Bolsonaro extinguiu o Conselho Nacional de Segurança Alimentar e Nutricional (Consea) com a Medida Provisória no 870/2019. ANELLI, André. Bolsonaro extingue Conselho Nacional de Segurança Alimentar e Nutricional. Brasília. Disponível em https://canalrural.uol.com.br/noticias/bolsonaro-conselhoseguranca-alimentar/. Acesso em 05 de agosto de 2019.
} 
intitular. Talvez esteja mais longe de um modelo mais assentado do que as Cartas no novo constitucionalismo". (OLIVEIRA; STRECK, 2012, p. 36).

Por tudo o que foi exposto, percebe-se que o Novo Constitucionalismo Latino Americano pode contribuir para políticas de proteção e de reconhecimento de direitos no Brasil.

\section{CONCLUSÃO}

O constitucionalismo latino americano até pouco tempo representou um mimetismo teórico vivido pelos países do norte do globo, apresentando assim características da colonialidade.

Diante de uma crise econômica e social a qual este constitucionalismo não conseguiu cuidar, pois foi baseado em vivências europeias, alguns países latinos voltaram-se para reformas sócio-legais, adotando documentos constitucionais mais robustos e garantidores no que se refere aos direitos sociais, econômicos e culturais, além do fortalecimento da soberania popular e da afirmação de estados multiculturais através do movimento do Novo Constitucionalismo Latino-Americano.

O neoconstitucionalismo europeu é considerado uma doutrina do Direito, possui como características o reconhecimento de um amplo catálogo de direitos fundamentais, a afirmação da força normativa da Constituição, a ampliação do poder jurisdicional sobre o poder legislativo; além da afirmação do direito em uma dimensão principiológica e do uso de técnicas ponderativas voltadas para a interpretação.

Decerto que o neoconstitucionalismo refundou o Estado brasileiro em relação a dinâmica do ordenamento jurídico pátrio através da elevação da Constituição Federal ao lugar de maior hierarquia e respeitabilidade, aliado ao uso dos princípios e do vasto catálogo de direitos postos para a proteção do cidadão, além dos instrumentos utilizados na aplicação do Direito, como a interpretação e seus recursos.

Entretanto, hodiernamente o cenário brasileiro tem se mostrado cheio de retrocessos a respeito dos direitos e das garantias do cidadão, necessitando, por conta disso, de uma nova visão sobre as relações que o Direito tem com a sociedade. Embora o Novo Constitucionalismo latino ainda não seja uma doutrina adotada pelo Brasil, este movimento 
traz um norte a ser seguido no que diz respeito ao reconhecimento de direitos e a proteção que o Estado deve dar as minorias sociais e ao meio ambiente.

\section{REFERÊNCIAS}

BARROSO, Luís Roberto. A constitucionalização do direito e suas repercussões no âmbito administrativo. In: ARAGÃO, Alexandre Santos de; MARQUES NETO, Floriano de Azevedo (Coord.). Direito Administrativo e seus novos paradigmas. Belo Horizonte: Fórum, 2008.

- Neoconstitucionalismo e constitucionalização do direito. (o triunfo tardio do direito constitucional no Brasil). Revista eletrônica sobre a reforma do Estado (RERE), Salvador, Instituto Brasileiro de Direito Público, nº. 9, mar/abr/mai, 2007. Disponível em: HTTP://direitodoestado.com.br/rere.asp. Acesso em: 31 de julho de 2019.

O constitucionalismo democrático no Brasil: crônica de um sucesso imprevisto. In: GUERRA, Roberta Freitas; SILVA, Fernando Laércio A. da; DELNERO, Patrícia Aurélia (Edit.). Neoconstitucionalismo em perspectiva. Viçosa: UFV, 2014.

Disponível emhttp://www.luisrobertobarroso.com.br/wpcontent/uploads/2017/09/constitucionalismo_de mocratico_brasil_cronica_um_sucesso_impre visto.pdf. Acesso em: 05 de agosto de 2019.

- Vinte anos da Constituição de 1988: a reconstrução democrática do Brasil. In: Revista de informação legislativa, v. 45, n. 179, p. 25-37, jul./set. 2008.

BARBOSA, Maria Lúcia and TEIXEIRA, João Paulo Allain. Neoconstitucionalismo e Novo Constitucionalismo Latino Americano: dois olhares sobre igualdade, diferença e participação. Revista Direito \& Práxis. Vol.8, n.2. 2017.

BARCELOS, ANA PAULA DE. Revista de Direito Administrativo, Rio de Janeiro, 240: 83103, Abr./Jun. 2005.

BRASIL. Constituição da República Federativa do. Brasília, DF, Senado, 1998.

BOLIVIA. Constituicióndel Estado Plurinacional de Bolivia. 2009. Disponível em: http://www.presidencia.gob.bo/documentos/publicaciones/constitucion.pdf. Acesso em: 20 ago. 2013.

CONSELHO NACIONAL DE JUSTIA. Perfil Sociodemográfico dos Magistrados Brasileiros 2018. Disponível em https://www.conjur.com.br/2018-set-13/maioria-judiciariohomensbrancos-casados-mostra-pesquisa. Acesso em 31 de agosto de 2019.

DALMAU, RúbenMartinez. El nuevo constitucionalismo latino-americano y el projecto de Constitución del Ecuador. Revista AletrJusticia, n.1. Guayaquil, oct. 2008, p. 17-27. Corte 
Constitucional de Ecuador para el período de transición. El nuevo constitucionalismo em América Latina. 1 ed. Quito, Corte Constitucional delEcuador, 2010. 96 p.

DIMOULIS, Dimitri. Dicionário brasileiro de direito constitucional/ coordenador-geral DimitriDimoulis. - 2. ed. — São Paulo: Saraiva, 2012.

ECUADOR. Constituición de la Republica del Ecuador.2008. Disponível em: http://www.asambleanacional.gov.ec/documentos/constitucion_de_bolsillo.pdf. Acesso em: 17 de julho de 2019

FERREIRA FILHO, Manoel Gonçalves, Curso de direito constitucional. - 38. ed., rev. E atual. - São Paulo: Saraiva 2012.

GODOY, Miguel Gualano de. Constitucionalismo e democracia: uma leitura a partir de Carlos Santiago Nino e Roberto Gargarella (Coleção direito, desenvolvimento e justiça: série produção científica). São Paulo: Saraiva 2012.

MONTEIRO, Arthur Maximus. Direito como ciência: crítica à doutrina neoconstitucionalista. Revista Direito e Liberdade, Natal, v. 19, n. 3, p. 43-67, set./dez., 2017. Quadrimestral.

NETO, Joaquim Shiraishi; ARAÚJO, Marlon Aurélio Tapajós. "BuenVivir": notas de um conceito constitucional em disputa. Pensar, Fortaleza, v. 20, n. 2, p. 379-403, maio/ago. 2015.

OLIVEIRA, Fábio Corrêa Souza de. STRECK, Lenio Luiz. O Novo Constitucionalismo Latino-Americano: reflexões sobre a possíbilidade de Construção de um Direito Constitucional Comum. In Para além das fronteiras [recurso eletrônico]: o tratamento jurídico das águas na UNASUL Parte II. MORAES, Germana de Oliveira (Org.). Itajaí: UNIVALI,2012.

SARMENTO, Daniel. O neoconstitucionalismo no Brasil. In: LEITE, George Salomão; SARLET, Ingo. Wolfgang (Coord). Direitos Fundamentais e Estado Constitucional: estudos em homenagem a J.J. Gomes Canotilho. São Paulo: RT, 2008

TOLENTINO, Zelma Tomaz; OLIVEIRA, Liziane Paixão Silva (2015). "Pachamama e o Direito à Vida: uma reflexão na perspectiva do novo constitucionalismo latino-americano" In: Revista Veredas do Direito. Vol. 12, n. ${ }^{\circ}$ 23. Belo Horizonte, p. 313-335.

WOLKMER, Antônio Carlos. Pluralismo e crítica do constitucionalismo na América Latina. SIMPÓSIO DE DIREITO CONSTITUCIONAL DA ABSCONST. IX. Anais eletrônicos. Curitiba: ABDCONST. 2011, p.143-155. Disponível em: http://www.abdconst.com.br/revista3/antoniowolkmer. pdf. Acesso em: 05 de agosto de 2019. 